* Doutora em Direito do Estado pela PUC/SP. Professora na UEL e PUC/PR. E-mail: mkempferb@gmail. com

** Mestrando em Direito Negocial pela Universidade Estadual de Londrina (UEL). Advogado. Especialista Direito Tributário pelo Instituto Brasileiro de Estudos Tributários (IBET), Especialista em Direito Civil e Processo Civil pela Universidade Estadual de Londrina (UEL). E-mail: eduardo@dmmadvogados. com.br

\section{Desenvolvimento tecnológico e a indução jurídica em face da Constituição do Brasil de 1988}

\author{
AcCording the 1988 Constitution of \\ BRAZIL TECHNOLOGICAL DEVELOPMENT AND THE \\ LEGAL INDUCEMENT \\ * Marlene Kempfer \\ ** Eduardo Ayres Diniz de Oliveira
}

Resumo: A Constituição Brasileira de 1988 enaltece no Art. 219 que o mercado interno, integra o patrimônio nacional e será incentivado para possibilitar a autonomia tecnológica do país. Em face desta norma constitucional e das competências para intervenção do Estado sobre o domínio econômico (Art. 174 $\mathrm{CF} / 88$ ) destaque-se a indução como o caminho para atrair os setores da atividade econômica privada nesta empreitada. A temática de inovações, inclusive, as tecnológicas impõem atenção e devem ser tratadas no nível de setor estratégico para o desenvolvimento socioeconômico conforme propõe Joseph Schumpeter. Neste sentido têm os governos competência constitucional, nos termos do Art. 218, para intervir em favor dos investimentos públicos e privados no âmbito dasciências, pesquisa e capacitação tecnológicas. Este dever tem por fundamento a concretização dos objetivos constitucionais de garantir o desenvolvimento nacional (Art. $3^{\circ}$, II). É o caminho que Norberto Bobbio denomina do uso das técnicas de encorajamento que, por sua vez, não abandonam a imagem tradicional do direito como ordenamento protetor-repressivo. Mas, enaltece a função promocional do Estado em sua legítima atribuição socioeconômica desenvolvimentista, conforme defende John Maynard Keynes.

Palavras-chaves: Normas jurídicas indutoras; Estado desenvolvimentista; Incentivos à inovação.

Abstract: The 1988 Constitution of Brazil extols in Art. 219 that the internal market integrates the national patrimony and will be encouraged to provide the technological autonomy of the country. According this constitutional provision and the competences for state intervention on economic domain (Art . $174 \mathrm{CF} / 88$ ) stands out the inducement as the way to attract the private sectors of economic activity in this endeavor. The theme of innovation, including, the technological ones, requires attention and must be treated at the level of strategic sector for 
socioeconomic development as proposed by Joseph Schumpeter. In this sense governments have constitutional power under Art. 218 to intervene on behalf of public and private investments in the context of science, research and technological expertises. This duty is based on the achievement of theconstitutional purpose of ensuring national development (Art. 3, II). It is the course that Norberto Bobbio denominates encouragement techniques which do not abandon the traditional image of law as protector-repressive system.But, praises the promotional function of the state in its legitimate socioeconomic developmental assignment, as John Maynard Keynes advocates.

Keywords: Incentive provisions; Developmental state; Inducements to innovation. 


\section{INTRODUÇÃO}

A intervenção do Estado sobre o domínio econômico está entre as competências dos governos conforme o Art. 174 da CF/88. Esta pesquisa está focada nesta atribuição, especificamente por meio do incentivo, tendo em vista as determinações constitucionais (Art. 218 e Art. 219) do dever do Estado em promover o desenvolvimento científico, a pesquisa e a capacitação, cuja finalidade é proporcionar o bem-estar da população e o caminho para autonomia tecnológica do País.

Na atualidade a tecnologia é apontada, para as iniciativas privada e pública, como o caminho para o desenvolvimento econômico. Além das importantes discussões éticas sobre o tema, centradas na bioética por exemplo, há o aspecto econômico. Entre os economistas que estudam este viés tem destaque o modelo de Joseph Schumpeter. Ele propõe que a tecnologia aplicada à inovação é um trajeto seguro para avanços de um país. Mais precisamente, enaltece que é importante gerar oportunidades para a criação empresarial, pois entre outras externalidades positivas, promove a expansão de negócios, redução de custos, geração de empregos e novos hábitos de consumo.

O papel do Estado neste modelo está em incluir nas políticas públicas os instrumentos de fomento. Esta intervenção é apoiada pela teoria econômica de John Maynard Keynes, que revendo o pensamento do liberalismo do laissezfaire, propõe a alternativa de enfrentar desequilíbrio econômico com a interferência estatal.

Embora não tenha tratado especificamente sobre questões de políticas tecnológicas é possível apoiar-se neste pensamento econômico para justificar a importância dos recursos públicos investidos no setor estratégico ora em estudo.

Quanto ao aspecto jurídico, os estudos de Norberto Bobbio contribuem quando tratam das iniciativas do incentivo ou fomento sob a denominação de técnicas de engajamento. São formas de recompensa pela conduta realizada nos termos que o Direito deseja ou por meio da facilitação da conduta que pretende encorajar.

O controle jurídico destas iniciativas é importante, pois atrai a temática da possibilidade do Judiciário avaliar a constitucionalidade e legalidade da elaboração (Legislativo) e execução (Executivo) das políticas públicas econômicas. Estas se constroem desde a previsão em lei do plano plurianual, da indicação dos instrumentos a serem empregados nas diretrizes orçamentárias e serão executadas se houver previsão efetiva de recurso no orçamento. 
Os paradigmas da igualdade e da livre concorrência devem ser considerados na avaliação judicial, após admitir-se que a determinação constitucional dos artigos 218 e 219 devem ser consideradas políticas do Estado. Assim é dever dos governos implementá-las.

\section{O ESTADO DESENVOLVIMENTISTA BRASILEIRO}

A Constituição de 1988 em seu Art. $3^{\circ}$, inciso II, aponta entre os objetivos fundamentais da República Federativa do Brasil o de garantir o desenvolvimento nacional. Para a acepção econômica, conforme registra Galves (2004, p.418419), "a teoria do desenvolvimento econômico, ou de expansão econômica, busca fornecer a chave do desenvolvimento, da involução e da estagnação" e estesmovimentos tem o seguinte significado:

[...] crescimento indica o aumento do produto nacional em taxa superior ao aumento da população; progresso indica a marcha rumo a uma sociedade caracterizada pela abundância de bens (o ter), e pela alta qualidade de vida (o ser); evolução indica a simples passagem de uma situação a outra que pode ser melhor ou pior que a anterior; e expansão indica todos estes tipos de movimento. (GALVES, 2004,p.418)

A questão que ora é destacada se refere a responder se o desenvolvimento de um país ocorre de modo espontâneo ou deve ser dirigida por meio da intervenção do Estado denominada de economia com planificação? Neste caso quais os meios eficientes de intervenção, especialmente, nos países em desenvolvimento que não podem esperar mais décadas para curar as feridas decorrentes da exclusão de direitos mínimos existenciais?

Embora a unanimidade a esta resposta seja dificílima em face das diversas escolas econômicas (liberalismo, socialismo e neoliberalismo), defende-se que os dizeres da atual Constituição brasileira asseguram competências para que os governos atuem de modo interventivo sobre as relações econômicas. Quer seja na condição de agente econômico (Art. 173) ou por meio normativo, fiscalizador, incentivo e planejamento (Art. 174). No entanto, defende-se que as formas interventivas devem fazer parte de um planejamento de modo que orientem não somente aos governos, mas também a iniciativa privada.

Conforme escreve Galves (2004, p.462) o Brasil a partir do regime democrático em 1946 "conheceu primeiro planificações especiais, depois, planificações regionais e, finalmente, planificações nacionais.” Estas, aponta, 
iniciaram a partir dos governos militares (1964), sendo o primeiro de autoria de Roberto Campos (1964-1966); seguiu-se com Hélio Beltrão (1966-1969) e o terceiro de Reis Veloso (1969-1972). Entre as várias metas (controle de inflação, reformas estruturais, aumento do produto interno bruto), destaque-se a preocupação com a política industrial para que o Brasil pudesse tornar-se menos dependente das importações.

Entre inúmeros e importantes economistas brasileiros, especial destaque em defesa de política econômica intervencionista deve-se a influência de Celso Furtado, apontado por ser "maior expoente do pensamento econômico desenvolvimentista". (GENNARI e OLIVEIRA, 2009, p. 339-340).

Para este economista a ideia basilar é que desenvolvimento envolve a acumulação de capital de forma ampla (para todos) e a adoção de processos produtivos mais eficientes - fora isto, nas demais hipóteses de aumento de renda não se terá desenvolvimento, mas sim modernização (FURTADO, 1981, p. 97). Válido destacar que o referido aumento de renda poderá ocorrer pela exploração de recursos naturais não renováveis e pela realocação de recursos visando a uma especialização num sistema de divisão de trabalho, mas nestes casos não há desenvolvimento se vierem desacompanhados da acumulação mencionada e dos processos produtivos mais eficientes. Nesta passagem o autor trata do que muitas vezes ocorre nos países subdesenvolvidos e reconhece que no Brasil houve esta realocação de recursos resultando em modernização. Nestes casos há uma grande parcela de consumidores de renda muita baixa em contrapartida a uma minoria de renda elevada, que desfavorece o desenvolvimento econômico, pois de um lado não há demanda para produção de bens diversificados a classe mais rica, e de outro a industrialização dos bens da cesta dos menos favorecidos não agrega um encadeamento, pois se utilizam dos bens da agricultura (indústrias têxteis e alimentícias) e já abastecem o consumidor final sem passar por outros processos de industrialização (FURTADO, 1981, p. 98). Neste caso para que houvesse o desenvolvimento econômico o necessário é que ao lado da utilização da mão de obra fosse acrescido um incremento na massa salarial de forma a gerar demanda ao mercado interno para propiciar que novas indústrias pudessem florescer e ser economicamente viáveis - como ocorrera nos países desenvolvidos.

Celso Furtado defendia que a industrialização era o caminho para o desenvolvimento, ideia que aprofundou na Comissão Econômica para a América Latina e Caribe (CEPAL), criada em 1948 junto a ONU e da qual fez parte em 1949 no Chile. Por meio do caminho que apontou defendeu que o Brasil superaria 
o papel de exportador de bens primários (bens que não sofreram transformação alguma). Esta superação viria a partir de um planejamento para identificar os setores frágeis e para programar medidas de antecipação que permitam dotar a estrutura produtiva de flexibilidade para atender as necessidades da demanda. Seria necessário absorver a tecnologia externa para assegurar as condições perenes de crescimento (GENNARI e OLIVEIRA, 2009, p. 343-344).

Em todo período pós-regime militar, os governos de José Sarney (19851990), Fernando Collor de Melo (1990-1992), Itamar Franco (1992-1994), Fernando Henrique Cardoso (1995-2002) e Luiz Inácio Lula da Silva (20032011), não tiveram alternativa quanto à economia brasileira ser ou não dirigida. Pode-se afirmar que divergiram, apenas, quanto ao grau da presença estatal. As instabilidades econômicas refletidas em períodos de crises (recortando apenas o período a partir de 1988) exigiram dos governos políticas econômicas fortemente intervencionistas e com repercussão expressiva na vida privada, entre elas: abertura comercial possibilitando investimentos estrangeiros; renegociação da dívida externa; desestatização de empresas estatais; reforma monetária; política cambial; poupança externa; controle de taxas de juros; metas de inflação e ajuste fiscal.

Atualmente a Constituição no capítulo que trata sobre orçamento público prevê que os governos, para sua gestão, devem planejar (Art. 165)por meio das Leis do Plano Plurianual(inciso I), da lei de diretrizes orçamentárias (inciso II) e orçamento anual (inciso III). Por meio delas irão apontar metas, políticas públicas e valores de investimentos sinalizando e influenciando políticas públicas econômicas. É rotineiro que nos planos plurianuais constem metas para enfrentamento dos problemas econômicos por meio de políticas econômicas, entre elas aponta Mendes (2002, p. 105-109), as de estabilidade com controle da inflação, melhorar a distribuição de rendas, crescimento de produção para gerar mais renda e emprego e o equilíbrio das contas externas.

Um Estado desenvolvimentista deve se envolver por meio de suas competências constitucionais e legais para atender, também, os interesses do mercado interno. E a efetividade desta intervenção depende das leis acima referidas e enumeradas no Art. 165 da CF/88. É a necessária conjugação dos interesses públicos e privados. Para exemplificar a coordenação entre plano plurianual, diretrizes orçamentárias e orçamento, tem-se: i)com o objetivo de atender o aumento de demanda energética ou em busca de autonomia neste setor (plano plurianual), o governo poderá destinar investimentos para a construção de uma usina hidrelétrica (lei de diretrizes orçamentárias) e definir 
o valor que reservará para sua execução (orçamento anual); esta é uma atuação governamental que interfere no comportamento dos agentes econômicos, pois estimulará ou garantirá aos empreendimentos econômicos privados previsibilidade nos seus investimentos; ii) poderá, em face da meta sobre a demanda energética, decidir sobre a prestação deste serviço público por meio de concessões (Art. $175 \mathrm{CF} / 88$ ); e ainda, iii) intervir por meio de regulação do setor. Atualmente estes marcos regulatórios (Art. 174 CF/88, a Lei das Concessões e Permissões no 8.987/95, criação da ANATEL por meio da Lei no 9472/97) também compõem o conjunto de políticas econômicas que são implementadas a partir de metas estabelecidas nos planos plurianuais.

\section{A PROPOSTADE INTERVENÇÃO DO ESTADO SOBRE O DOMÍNIO ECONÔMICODE JOHN MAYNARD KEYNES}

Tradicionalmente os economistas sistematizam os estudos econômicos em dois ramos: a micro e a macroeconomia. E conforme Mendes (2002, p.2122), a microeconomia se concentra na análise do comportamento dos consumidores e produtores (agentes econômicos) para buscar eficiência na maximização de resultados, a formação de preços e a estrutura de mercado. Segue o autor explicando que a macroeconomia por sua vez reúne os conhecimentos do sistema econômico como um todo para explicar, entre outros aspectos, as contas do setor público, desenvolvimento socioeconômico, balanço de pagamentos, relações entre investimentos, déficit público, taxas de juros e níveis de emprego.

A partir do exposto pode-se incluir os estudos de John Maynard Keynes no ramo da macroeconomia, identificada por Galves (2004, p. 426-427), por "Teoria Keynesiana do Desenvolvimento" e que alerta o autor não pode ser reduzida a "uma ótica ou lógica macroeconômica de curto prazo". As ideias do economista se concentram, especialmente, em defesa da intervenção do Estado sobre o domínio econômico, enfrentando os pensadores Neoclássicos que defendiam o livre mercado.

O britânico Keynes (1883-1946) faz críticas aos que defendem o laissezfaire. Afirmou que a liberdade econômica proposta pelo liberalismo clássico apoiava-se em princípios metafísicos ou gerais e os refuta. Além disto, deve-se determinar o que o Estado deve tomar para si para dirigir pela sabedoria pública e que deve deixar com tão pouca interferência quanto possível ao exercício dos indivíduos (BURKE apud KEYNES, 1978, p. 121). 
E nesta linha de raciocínio defende a importância em se estabelecer o que é a agenda do governo da não-agenda e que deve ser tarefa da política o estabelecimento das formas de governo capazes de realizar esta agenda (KEYNES, 1978, p. 120). Para ele o tamanho ideal de controle e organização estaria em algum ponto entre o individualismo e o Estado Moderno (KEYNES, 1978 , p. 121) e que o progresso estaria na criação de órgãos para atuação, unicamente, quanto ao bem público(KEYNES, 1978, p. 120).

Keynes também reconhece a importância de serem regulamentados determinados fatores que influem na atividade econômica de forma a assegurar que as incertezas deixem de servir de meio de favorecimento a uma pequena classe. Pois elas gerariam a desigualdade social, desemprego, frustração nas expectativas do empresário, redução da eficiência e da produção. E para o que ele denomina a cura para esses males, o Estado deve exercer um controle ou mesmo regulamentar a transparência das informações sobre: a moeda e o crédito (neste caso defende a criação de uma instituição central), poupança e o investimento, e até da população (KEYNES, 1978, p. 124).

Impende explicar que Keynes não se mostra como aversivo ao capitalismo, porém o que ele defende é a atuação do Estado para melhorar o capitalismo. Ou seja, um capitalismo sabiamente administrado para atingir objetivos econômicos de forma mais eficiente:

De minha parte, acho que, sabiamente administrado, o capitalismo provavelmente pode se tornar mais eficiente para atingir objetivos econômicos do que qualquer sistema alternativo conhecido, mas que, em si, ele é de muitas maneiras sujeito a inúmeras objeções. Nosso problema é o de criar uma organização social tão eficiente quanto possível, sem ofender nossas noções de um modo satisfatório de vida. (KEYNES, 1978, p. 125-126)

A importância de sua teoria está intimamente ligada a repercussão que ela teve no papel que o Estado passou a representar na intervenção sobre o domínio econômico. Ou seja, vários governos passaram a construir suas políticas econômicas a partir do modelo intervencionista por ele proposto, especialmente, para enfrentara grave crise do capitalismo liberal na década de 1930 que se instalou nos Estados Unidos no governo de Franklin Roosevelt, conhecida por período da "Grande Depressão".

O intervencionismo de Keynes destaca-se pelo objetivo maior de conduzir a economia a um regime de geração de emprego e, para tanto, deve-se manter o crescimento da demanda e da capacidade produtiva. Entre as medidas que 
compõem um conjunto de uma política econômica propõe a concessão de incentivos por meio de créditos públicos a baixo custo, principalmente, para estimular a produção e o consumo em momentos em que as empresas deem sinais de recuo em investimentos e mercado com redução do consumo.

\section{OS DESAFIOS DAS INOVAÇÕES DE JOSEPH SCHUMPETER}

Foi Joseph Alois Schumpeter (1883-1950), nascido onde vem a ser atualmente a República Tcheca, quem reconheceu o importante papel que as novas formas de combinações dos fatores de produção tem no meio econômico. Destaca-se a obra “A Teoria do Desenvolvimento Econômico"(1911), oportunidade em que apresenta uma série de ideias envolvendo o empresário como um inovador e promotor do desenvolvimento.

Sua teoria procura encontrar dentro do meio social as ocorrências que favorecem o desenvolvimento em detrimento de outros economistas de sua época, que viam somente em fatores externos tais quais as guerras, aumento populacional entre outros.

Para compreensão de sua obra um termo inicial de suma importância é o fluxo circular. Segundo seu pensamento, parte-se do pressuposto de que haveria um funcionamento estacionário da economia que somente seria modificado pela atitude do empresário inovador:

No fluxo circular, do qual sempre partimos, os mesmos produtos são produzidos todos os anos da mesma maneira. Para cada oferta existe à espera uma demanda correspondente em algum lugar do sistema econômico, para cada demanda, uma oferta correspondente. Todos os bens são negociados a preços determinados com oscilações simplesmente insignificantes, de modo que se pode considerar que toda unidade de dinheiro percorre o mesmo caminho em cada período. Em qualquer momento uma dada quantidade de poder de compra está disponível para adquirir a quantidade existente de serviços produtivos originais, para então passá-los às mãos de seus proprietários e depois serem gastos novamente em bens de consumo. (SCHUMPETER, 1982, p. 75)

Esse andamento harmonioso somente deixaria de se repetir trazendo uma alteração e levando outro dinamismo a economia quando novas combinações fossem introduzidas. Explicitando melhor, entende por novas combinações as novas disposições, novas alocações dos fatores de produção ou ainda decorrente de uma inovação tecnológica. Produzir significa combinar materiais e forças 
que estão ao nosso alcance. Produzir outras coisas, ou as mesmas coisas com método diferente, significa combinar diferentemente esses materiais e forças. (SCHUMPETER, 1982, p. 48). Estas novas combinações podem vir por cinco formas:

1) Introdução de um novo bem - ou seja, um bem com que os consumidores ainda não estiverem familiarizados - ou de uma nova qualidade de um bem. 2) Introdução de um novo método de produção, ou seja, um método que ainda não tenha sido testado pela experiência no ramo próprio da indústria de transformação, que de modo algum precisa ser baseada numa descoberta cientificamente nova, e pode consistir também em nova maneira de manejar comercialmente uma mercadoria. 3) Abertura de uma novo mercado, ou seja, de um mercado em que o ramo particular da indústria de transformação do país em que questão não tenha ainda entrada, quer esse mercado tenha existido antes ou não. 4) Conquista de uma nova fonte de oferta de matériasprimas ou de bens semimanufaturados, mais uma vez independentemente do fato de que essa fonte já existia ou teve que ser criada. 5) Estabelecimento de uma nova organização de qualquer indústria, como a criação de uma posição de monopólio (por exemplo, pela trustificação) ou a fragmentação de uma posição de monopólio. (SCHUMPETER, 1982, p. 48-49, destaques nossos).

Define que empresário é aquele que realiza novas combinações. Reconhece que há casos em que o empresário (assim como antigamente) é visto como o sujeito que definia as estratégias, exercia função de agente de compras, responsável pelo departamento pessoal e arremata:

Mas, qualquer que seja o tipo, alguém só é um empresário quando efetivamente "levar a cabo novas combinações", e perde esse caráter assim que tiver montado o seu negócio, quando dedicar-se a dirigi-lo, como outras pessoas dirigem seus negócios. Essa é a regra, certamente, e assim é tão raro alguém permanecer sempre como empresário através das décadas de sua vida ativa, quanto é raro um homem de negócios nunca passar por um momento em que seja empresário, mesmo que seja em menor grau. (SCHUMPETER, 1982, p. 56).

Ele reconhece que exista sim nexo da mudança a partir das necessidades dos consumidores, porém para ele:

[...] é o produtor que, via de regra, inicia a mudança econômica, e os consumidores são educados por ele, se necessário; são, por assim dizer, 
ensinados a querer coisas novas, ou coisas que diferem em um aspecto ou outro daqueles que tinha o hábito de usar. (SCHUMPETER, 1982, p. 48).

Os termos "destruição criadora/criativa" remetem a sua teoria e se refere a alteração ocasionada ao ciclo de estagnação passando a um novo ciclo de crescimento. Sendo que o que faria esta evolução colocando em funcionamento a "máquina capitalista" seriam os "novos bens de consumo, dos novos métodos de produção ou transporte, dos novos mercados e das novas formas de organização industrial que a empresa capitalista cria." (SCHUMPETER, 1984, p. 112). Explica que após introdução do novo produto haveria um boom de pessoas que passariam a produzi-lo por imitação, cópia, e que geraria o desenvolvimento, pois leva a uma onda de investimentos de capital que por sua vez gera a riqueza e aumento do emprego.

A partir destas explicações quanto ao fluxo circular, às inovações, o papel do empresário e da destruição criadora defende que há uma íntima ligação entre a realização das novas combinações e o desenvolvimento.

Outro aspecto de sua teoria é a defesa de que somente o empreendedor necessita de crédito, pois este serviria ao desenvolvimento industrial. $\mathrm{O}$ crédito que se menciona aqui representa uma transferência temporária do poder de compra que é necessário para que as inovações ocorram, pois sem o crédito o capital fica limitado ao fluxo circular:

[...] crédito é primariamente necessário às novas combinações e que é por estas que ele força seu caminho dentro do fluxo circular, de um lado, porque foi necessário originalmente para fundação do que agora são as empresas antigas, e de outro, porque seu mecanismo, uma vez em funcionamento, também se apodera das combinações antigas por razões óbvias. (SCHUMPETER, 1982, p. 51).

Depreende-se que o modelo de inovação de Schumpeter parte do pressuposto que há um fluxo circular e que a economia no sistema capitalista funciona entre a criação e a destruição. O que causa a criação e a destruição é justamente a introdução de uma inovação e, respectivamente, o esgotamento desta inovação com o surgimento de uma nova.

Neste modelo, por ser cíclico, as inovações precisam ser estimuladas pelo crédito, crédito este oferecido ao industrial, pois é ele quem viabiliza o crescimento econômico e em última análise o desenvolvimento. 


\section{A ORDEM JURÍDICA E AS TÉCNICAS DE ENCORA- JAMENTO}

O conjunto normativo que compõem o estudo do Direito tem por desafio buscar resultados efetivos na condução das condutas das pessoas conforme as normas jurídicas. Este é o aspecto da eficácia social do ordenamento. O percurso tradicional é por meio das normas jurídicas sancionatórias em face de condutas antijurídicas, para desencorajá-las. No entanto, há âmbitos das relações humanas, tal qual é o do domínio econômico, em que tais normas são incompatíveis para o controle estatal das externalidade positivas resultantes das condutas inseridas neste domínio. Ou seja, a intervenção do Estado para estimular condutas que geram efeitos positivos na economia não poderá ser realizada por meio das normas sancionatórias, mas por meio de normas de estímulo a condutas que contribuam para atingir os objetivos do regime jurídico-econômico.

O apoio doutrinário a estes argumentos está em Norberto Bobbio que em estudos sobre a função promocional do direito se debruçou com propriedade sobre a temática das sanções premiais. Rememora o doutrinador que, em realidade, o termo sanção comporta tanto um aspecto negativo como positivo, ou seja, tanto uma situação prejudicial, sanção negativa, como benéfica, sanção positiva:

Na literatura filosófica e sociológica, o termo "sanção" é empregado em sentido amplo, para que nele caibam não apenas as consequências desagradáveis da inobservância das normas, mas também as consequências agradáveis da observância, distinguindo-se, no genus sanção, duas species: as sanções positivas e as sanções negativas. Ao contrário, é fato que, na linguagem jurídica, o termo "sanção", se for usado sem determinações ulteriores, denota exclusivamente as sanções negativas.(BOBBIO, 2007, p.7)

Reconhece que se de um lado o Direito é majoritariamente visto como um sistema protetor-repressivo que se ocupa, principalmente, em estabelecer determinados comportamentos e sanções negativas pelos seus descumprimentos. Neste sentido, Kelsen (2000, p. 37) afirma que o Direito é uma ordem coativa que estatui uma consequência para uma situação de fato considerada socialmente prejudicial, que eventualmente algumas ordens jurídicas detêm recompensas, porém em sua visão elas não configuram a função essencial do Direito e desempenham apenas um papel subalterno. Para Jhering (1946, p. 93), a sociedade castiga aos que contra ela delinquem e recompensa os que a 
servem, sendo que ao fazer um comparativo com a antiguidade chegou a conclusão de que atualmente mais se castiga.

De toda forma, atualmente cresce uma forma de intervenção do Estado que Bobbio denomina de técnicas de encorajamento:

Ao contrário, isso se dá pelo que observei inicialmente: no Estado contemporâneo, torna-se cada vez mais frequente o uso das técnicas de encorajamento. Tão logo comecemos a nos dar conta do uso dessas técnicas, seremos obrigados a abandonar a imagem tradicional do direito como ordenamento protetor-repressivo. Ao lado desta, uma nova imagem toma forma: a do ordenamento jurídico como ordenamento com função promocional. [...]Em poucas palavras, é possível distinguir, de modo útil, um ordenamento protetivo-repressivo de um promocional com a afirmação de que, ao primeiro, interessam, sobretudo, os comportamentos socialmente não desejados, sendo seu fim precípuo impedir o máximo possível a sua prática; ao segundo, interessam, principalmente, os comportamentos socialmente desejáveis, sendo seu fim levar a realização destes até mesmo aos recalcitrantes. (BOBBIO, 2007, p. 13).

Norberto Bobbio explicita que as técnicas do encorajamento permitem ao Estado atuar promovendo uma recompensa pela conduta realizada nos termos que o Direito deseja, ou por meio da facilitação da conduta que pretende encorajar, em suas palavras:

Com particular atenção às técnicas de encorajamento, note-se a diferença entre as duas operações: a sanção propriamente dita, sob forma de recompensa, vem depois, com o comportamento já realizado; a facilitação precede ou acompanha o comportamento que se pretende encorajar. Em outras palavras, pode-se encorajar intervindo sobre as consequências do comportamento ou sobre as modalidades, sobre as formas, sobre as condições do próprio comportamento. Para oferecer um exemplo retirado da vida comum temos: se desejo que meu filho faça uma tradução difícil do latim, posso prometer-lhe, se ele a fizer, irmos ao cinema, ou então posso permitir que utilize uma tradução bilíngue. (BOBBIO, 2007, p. 17).

O jus-filósofo italiano argumenta que por meio da técnica do encorajamento pode o Direito promover condutas desejadas e as indicadas poderiam ser subvenções, contribuições financeiras, facilitação de crédito, isenções fiscais (BOBBIO, 2007, p. 18). Por meio destes caminhos, sublinha, tende-se a induzir certos empreendedores a modificar a situação existente 
enquanto o desincentivo tende a induzir outros empreendedores à inércia. (BOBBIO, 2007, p. 20)

Avaliando a atual ordem constitucional econômica brasileira (1988), podese afirmar que os governos têm competência para recorrer a estas técnicas de encorajamento e dirigi-las para o domínio econômico:

Art. 174. Como agente normativo e regulador da atividade econômica, o Estado exercerá, na forma da lei, as funções de fiscalização, incentivo $e$ planejamento, sendo este determinante para o setor público e indicativo para o setor privado. (BRASIL, 1988, destaque nosso).

É a possibilidade de intervenção do Estado sobre o domínio econômico a que se refere Eros Grau (2008, p. 147-148), por meio de indução dirigida a condutas em setores de relevante interesse público, tal qual é o domínio econômico. Estimular as externalidades positivas desta atividade poderá aproximar as iniciativas públicas das privadas para a realização de objetivos comuns. Entre eles, especialmente, em investimentos estratégicos que promovam o desenvolvimento socioeconômico (Art. $3^{\circ}$, II CF/88).

Defende-se que a eficiência das técnicas de encorajamento utilizadas pelos governos dependerá, em alto grau, da compreensão da racionalidade do âmbito para os quais elas se destinam. Neste sentido aponta-se a importância do conhecimento interdisciplinar. Por meio do Direito é possível sancionar negativa ou positivamente, mas a eficiência medida pela adesão aos meios encorajadores dependerá da compreensão do agir das pessoas, das instituições, dos seus interesses e dos valores que as orientam. Por exemplo, o domínio das relações econômicas move-se pelos valores da eficiência que se alcança percorrendo os caminhos da economicidade para maximizar o lucro. Para tanto, as empresas se organizam de forma a encontrar um sistema de gestão que atenda a estes valores. Estes são desafios da Economia e da Ciência da Administração de Empresas. Portanto, para o Estado intervir eficientemente deve considerar tais conhecimentos.

As opções governamentais dependerão das políticas econômicas que adotam. Há governos que se filiam às ideias de menor e outros em favor da maior intervenção do Estado sobre o domínio econômico. Por exemplo, para pensadores da Escola do Neoliberalismo que tem entre seus membros Friedrich Von Hayek, o papel do Estado não é o de criação de uma ordem social. Para ele isto não seria possível de antever. Segundo sua doutrina, não é possível a um governo tentar predeterminar a sociedade, pois o fenômeno social é muito 
complexo e não pode ser direcionado, e para tanto, caberá aos governos assegurarem condições ótimas para o inconsciente e natural desenrolar das deliberações sociais (HAYEK, apud BUTLER, 1987, p. 111-112). Diferentemente é a percepção do mesmo fenômeno por John Maynard Keynes, conforme já exposto linhas atrás.

Os desafios dos governos para escolher estas técnicas estão em analisar qual delas é a mais eficiente e que possam atender aos valores e normas constitucionais que compõem o arcabouço jurídico-econômico do Estado. Para o Brasil os limites positivos estão estampados, especialmente, no texto do Art. 170 da CF/88. Ou seja, nos termos deste artigo os estímulos devem ser dirigidos ao domínio econômico para prestigiar atuações empresariais que promovam, por exemplo: a geração de empregos (inciso VIII); investimentos em novas tecnologias de respeito ao ambiente (inciso VI); que atraiam as pessoas do mercado informal (inciso IX); para as empresas dispostas a investir em regiões de menor desenvolvimento socioeconômico(inciso VII). Os limites negativos devem considerar que os estímulos não podem afetar a livre concorrência (inciso IV) ou as relações de consumo (inciso V).

\section{AS INDUÇÕES JURÍDICAS PARA O DESENVOLVIMENTO TECNOLÖGICO EA CONSTITUIÇÃO FEDERAL DE 1988}

A atual Constituição registra a opção do Estado brasileiro por políticas públicas no setor da ciência e tecnologia, nos seguintes termos:

Art. 218. O Estado promoverá e incentivará o desenvolvimento científico, a pesquisa e a capacitação tecnológicas.

$\S 1^{\circ}$ - A pesquisa científica básica receberá tratamento prioritário do Estado, tendo em vista o bem público e o progresso das ciências.

$\S 2^{\circ}$ - A pesquisa tecnológica voltar-se-á preponderantemente para a solução dos problemas brasileiros e para o desenvolvimento do sistema produtivo nacional e regional.

$\S 3^{\circ}$ - O Estado apoiará a formação de recursos humanos nas áreas de ciência, pesquisa e tecnologia, e concederá aos que delas se ocupem meios e condições especiais de trabalho.

$\S 4^{\circ}$ - A lei apoiará e estimulará as empresas que invistam em pesquisa, criação de tecnologia adequada ao País, formação e aperfeiçoamento de seus recursos humanos e que pratiquem sistemas de remuneração que assegurem ao empregado, desvinculada do salário, participação nos ganhos econômicos resultantes da produtividade de seu trabalho. 
$\S 5^{\circ}$ - É facultado aos Estados e ao Distrito Federal vincular parcela de sua receita orçamentária a entidades públicas de fomento ao ensino e à pesquisa científica e tecnológica.

Art. 219. O mercado interno integra o patrimônio nacional e será incentivado de modo a viabilizar o desenvolvimento cultural e sócio-econômico, o bemestar da população e a autonomia tecnológica do País, nos termos de lei federal. (BRASIL, 1988).

Sendo assim, os governos devem elaborar e executar políticas que efetivem tais normas constitucionais. Elas podem ser direcionadas para a própria administração pública por meio, por exemplo, das universidades ou institutos de pesquisa e também para a iniciativa privada.

O investimento público neste setor poderá contribuir para as inovações apontadas no modelo de Schumpeter. Conforme exposto acima, inclui iniciativas de introdução de um novo bem, de um novo método de produção, abertura de um novo mercado, conquista de uma nova fonte de oferta de matérias-primas ou de bens semimanufaturados até mesmo o estabelecimento de uma nova organização de qualquer indústria.

Estes exemplos dirigidos ao âmbito econômico são inovações que interessam ao desenvolvimento do Estado. Dependem de pesquisa científica, capacitação tecnológica e produção. Tais iniciativas podem vir exclusivamente da iniciativa privada, mas em um Estado de opção desenvolvimentista é legítimo acelerar tais processos por meio, por exemplo, de políticas industriais. Estas conforme Schapiro (2011, p. 73), compreendem um conjunto de medidas previstas para ensejar o favorecimento do setor produtivo como um todo. Enfatiza que em regra estas medidas procuram combinar medidas de fomento e disposições regulatórias para direcionar os recursos para este setor, indústria.

Doutrinadores da Ciência da Administração, Jugend e da Silva (2013, p.57), apontam que dentre os fatores que constam no Manual de Oslo, proposto pela Organização para a Cooperação e Desenvolvimento Econômico (OCDE) (BRASIL, 2014b) e que influenciam a dinâmica da inovação tecnológica, estão as condições estruturais que foram destacadas para este estudo:

As Condições Estruturais correspondem aos fatores básicos que suportam as atividades de inovação em um país. Destacam-se, nesse quesito, a presença de sistema educacional básico (que gere mão de obra minimamente qualificada); condições de infraestrutura, o que inclui padrão de sistemas de comunicação e internet, fornecimento e custo de itens como energia elétrica 
e água, e logística adequada (rodovias, ferrovias, portos, por exemplo); legislação e estímulos legais à inovação (como a lei de inovação atualmente em vigor no Brasil); proximidade e acessibilidade ao mercado consumidor e presença e proximidade dos principais fornecedores. Cabe atentar que no Brasil o sistema educacional básico, infraestrutura e legislação são fatores que apresentam significativos problemas e dificultam atividade de inovação e consequentemente a competitividade de grande parte das nossas empresas. (destaques nossos).

Pode-se avaliar que a partir da análise dos estudos econômicos e de gestão empresarial avançar no desenvolvimento tecnológico é um desafio a ser enfrentado pelos governos e iniciativa privada. Nos termos retrorreferidos ao Estado compete investimentos em educação para capacitação tecnológica, infraestrutura e leis que recompensem aqueles que se unem para este desafio. Neste caso em especial, os instrumentos são os fomentos públicos a serem oferecidos pela técnica do encorajamento sobre as quais tão bem expõe Norberto Bobbio.

Para tais políticas econômicas os governos têmautorização constitucional para incluir nos orçamentos recursos públicos:

165. Leis de iniciativa do Poder Executivo estabelecerão:

$[\ldots]$

$\S 2^{\circ}$ - A lei de diretrizes orçamentárias compreenderá as metas e prioridades da administração pública federal, incluindo as despesas de capital para o exercício financeiro subseqüente, orientará a elaboração da lei orçamentária anual, disporá sobre as alterações na legislação tributária e estabelecerá $\boldsymbol{a}$ política de aplicação das agências financeiras oficiais de fomento.(BRASIL, 1988, destaque nosso).

As agências de fomento público são instituições que possibilitam oferecer recursos ao setor privado para setores estratégicos. Entre as agências federais, por exemplo, está o Banco do Brasil, Caixa Econômica, Banco de Desenvolvimento Econômico e Social (BNDES),Financiadora de Estudos e Projetos (FINEP) vinculada ao Ministério da Ciência, Tecnologia e Inovação (MCTI), Serviço Brasileiro de Apoio a Micro e Pequena Empresa (SEBRAE). Nos termos do Banco Central do Brasil, tais agências têm como objeto social:

[...] a concessão de financiamento de capital fixo e de giro associado a projetos na Unidade da Federação onde tenham sede. Devem ser constituídas sob a forma de sociedade anônima de capital fechado e estar sob o controle de 
Unidade da Federação, sendo que cada Unidade só pode constituir uma agência. Tais entidades têm status de instituição financeira, mas não podem captar recursos junto ao público, recorrer ao redesconto, ter conta de reserva no Banco Central, contratar depósitos interfinanceiros na qualidade de depositante ou de depositária e nem ter participação societária em outras instituições financeiras. De sua denominação social deve constar a expressão "Agência de Fomento" acrescida da indicação da Unidade da Federação Controladora. É vedada a sua transformação em qualquer outro tipo de instituição integrante do Sistema Financeiro Nacional. As agências de fomento devem constituir e manter, permanentemente, fundo de liquidez equivalente, no mínimo, a $10 \%$ do valor de suas obrigações, a ser integralmente aplicado em títulos públicos federais. (BRASIL, 2014a)

Bresser-Pereira (2009, p.281-288) ao tratar do modelo básico para a gestão pública e a redefinição dos papéis do Estado inclui como atuação monopolista dos governos "promover ou assegurar os objetivos políticos fundamentais que as sociedades modernas estabeleceram para si”, e aponta entre elas o desenvolvimento econômico por meio de políticas públicas incluindo as políticas econômicas. É o caminho aberto para a interação público-privada que faz parte dos ideais da reforma do Estado trazida com a Emenda Constitucional no 19/98. Esta atuação conjunta, típica de estados desenvolvimentistas, embora possam ser defendidas no nível de prerrogativa governamental, defende-se que devem ser consideradas políticas de Estado. Esta interpretação tem apoio nos argumentos intervencionistas de John Keynes, conforme suas principais ideias expostas anteriormente.

Entre as possibilidades de fomento ou incentivos públicos, conforme estudos de Pires (2003, p. 1113-1116), podem ser subdivididos em: i) subvenções, ii) créditos presumidos; e, iii) subsídios.

Escreve o autor que: i) as subvenções são doações que são feitas pelas pessoas jurídicas de direito público segundo sua conveniência política, podendo ser para custeio, em que a doação é feita para que a entidade privada condicionada a uma realização por parte dela tendo como propósito incentivar uma atividade que em condições normais não seria feita. Também podem ser para investimento, como um verdadeiro aporte, caso em que, são destinadas a entidade privada para realização de um fim específico pelo concedente. Em alguns casos, as subvenções por representarem verdadeira renúncia de receita, estão sujeitas as regras e princípios tributários; 
ii) Os créditos presumidos as vezes se comportam como subsídio, outras como subvenção ou então, mera redução da base de cálculo. São mais comuns nos impostos não-cumulativos(atualmente IPI, ICMS e as contribuições ao PIS/ Cofins);

iii) Os subsídios, que são "[...] toda ajuda oficial de governo, seja de natureza comercial, financeira, cambial ou fiscal, com o fim de estimular a produtividade de indústrias instaladas no país" (PIRES， 2003, p. 1113).Na categoria de subsídios fiscais compreendem as isenções, o diferimento, a remissão e a anistia. As isenções são normas emitidas pelos próprios entes detentores da competência tributária que reduzem o campo de incidência da norma que prevê a tributação por lhe retirar algum dos critérios da regra matriz de incidência tributária. O diferimento é uma subespécie de isenção, pois a rigor o tributo devido em determinada etapa da cadeia é postergado para etapa subsequente, atribuindo a lei a condição de sujeito passivo a outro sujeito de direitos. Aremissão e a anistia, não são propriamente modelos de redução de carga tributária, pois a primeira decorre de simples ato de liberação da obrigação nos termos do artigo 172 do Código Tributário Nacional. A segunda decorre de fato do príncipe pela liberação das penalidades conforme artigo 180 do referido código. Porém, podem ser consideradas como instrumentos de indução a determinadas atividades ou mesmo ferramentas de pacificação social.

O Brasil, na atualidade, conta com um conjunto normativo que registram as políticas públicas em favor do desenvolvimento tecnológico. A lei 10.973/04 é conhecida por ser o marco legal das inovações e estabelece em seu Art. $1^{\circ}$ que regulamentará "medidas de incentivo à inovação e à pesquisa científica e tecnológica no ambiente produtivo, com vistas à capacitação e ao alcance da autonomia tecnológica e ao desenvolvimento industrial do País, nos termos dos arts. 218 e 219 da Constituição" (BRASIL, 2004a).

Para implementação de suas medidas, entre outras iniciativas, por meio da lei 11.080/04 foi criado o Serviço Social Autônomo denominado Agência Brasileira de Desenvolvimento Industrial (ABDI)vinculado ao Ministério do Desenvolvimento, Indústria e Comércio Exterior (MDIC). Tem a finalidade nos termos do Art. $1^{\circ}$ dessa lei de "promover a execução de políticas de desenvolvimento industrial, especialmente as que contribuam para a geração de empregos, em consonância com as políticas de comércio exterior e de ciência e tecnologia."(BRASIL, 2004b).

Em termos concisos, a ABDI se propõe a atuar na aproximação entre os interesses do setor público e os da iniciativa privada. Para tanto poderá por 
exemplo disponibilizar informações técnicas, creditícias, entre outras que contribuam para o desenvolvimento industrial brasileiro(Art. $9^{\circ}$, III e IV) (BRASIL, 2004b).

Mais especificamente para a concretização dos objetivos constitucionais referentes à inovação, o Brasil tem a Secretaria de Inovação vinculada ao MDIC e que integra o Sistema Nacional de Ciência, Tecnologia e Inovação. Entre suas principais atividades, destaque-se: i)sugerir modalidades de incentivos fiscais, financeiros e regulatórios para o desenvolvimento e uso de tecnologias verdes; ii) promover parceria entre a atuação pública e a privada; iii) monitorar e avaliar políticas de inovação; iv) reorientar os instrumentos de apoio à inovação para a competitividade nas empresas.(BRASIL, 2014c)

Em face do exposto pode-se afirmar que o atual Estado brasileiro optou por governos desenvolvimentistas. Atuando por meio do Legislativo quando aprova as leis, a iniciar com o plano plurianual, diretrizes orçamentárias, orçamento, competências de intervenção com marcos regulatórios e políticas de fomento ao setor de desenvolvimento tecnológico. Segue com a implementação, por ação do Executivo, dos órgãos e de agências de fomentos. Resta, portanto, avaliar o papel do Judiciário diante das atribuições constitucionais do Art. $3^{\circ}$, III, Art. 218, Art. 219, Art. 165, § $2^{\circ}$.

Tradicionalmente ao Judiciário, em face das ações ou omissões dos agentes do Estado, é chamado para se manifestar sobre o regular exercício da competência do Legislativo e Executivo. Avalia-os por meio do controle de constitucionalidade e legalidade. Considerando a proposta desta pesquisa a questão que se analisa tem por foco responder as seguintes principais indagações: o controle sobre as técnicas de encorajamento aplicadas por meio dos incentivos públicos pode ser interpretado como controle judicial de políticas públicas econômicas? Este controle seria possível na elaboração (Legislativo) e na execução (Executivo) destas políticas? Quais os parâmetros para este controle?

Reconhecendo a dificuldade do tema, especialmente em face das atuais discussões sobre a atuação com independência dos órgãos Legislativo, Executivo e Judiciário, defende-se que o controle deve ser possível partindo da seguinte premissa: o arcabouço constitucional a respeito da intervenção do Estado sobre o domínio econômico para desenvolvimento científico, a pesquisa e a capacitação tecnológicas dirigida a promover o bem-estar da população e a autonomia tecnológica do País é norma que compõe deveres do Estado, portanto deve, obrigatoriamente, ser cumprida pelos governos.

O controle judicial poderá ocorrer avaliando a necessidade de que tais políticas componham o planejamento público e, portanto, deve haver inserção 
nas leis do plano plurianual em forma de metas a serem alcançada pelo governo, seguindo pela instrumentalização nas diretrizes orçamentárias e a previsão de recursos no orçamento. A definição por meio de leis sobre o usufruto dos fomentos deverá considerar os princípios da igualdade e da livre concorrência e as seguintes prioridades nos termos do Art. 218 CF: I) recursos para órgãos públicos (em sentido amplo) que possam contribuir para as metas do plano plurianual. Nesta categoria os investimentos devem ter preferência: i) para pesquisa científica básica; ii) para pesquisa que contribua, preponderantemente, para a solução dos problemas brasileiros e para o desenvolvimento do sistema produtivo: a) preferência para pesquisas de alcance nacional; b) seguindo para aquelas de alcance regional; iii) para investimentos na formação de recursos humanos nas áreas de ciência, pesquisa e tecnologia, garantindo condições especiais de trabalho; II) recurso para fomentos dirigidos à iniciativa privada, a preferência deve ser: i)para aquelas empresas que invistam em pesquisa, criação de tecnologia adequada ao País; ii) que apresentem programa de formação e aperfeiçoamento de seus recursos humanos na área de tecnologias e inovações; iii) para aquelas que pratiquem sistemas de remuneração e assegurem ao empregado, desvinculada do salário, participação nos ganhos econômicos resultantes da produtividade de seu trabalho.

Quanto ao Princípio da Igualdade registre-se que o ideal seria que os recursos públicos fossem disponíveis a todos aqueles (órgão, empresas públicas ou empresas privadas) com interesse e condições de atuar no âmbito do desenvolvimento tecnológico. Mas o Estado tem muitas atribuições e há outros deveres fundamentais e que precisam ser atendidos. Assim, considerando o Princípio da Reserva do Possível, que limita a atuação financeira do Estado, os paradigmas para o controle do respeito a este princípio estão no texto constitucional e foram apontados em linhas anteriores.

A atuação do Estado intervindo por meio de fomentos ou na condição empresarial deve ser analisada à luz das questões concorrenciais. A empresa que investe em inovação, nos termos do modelo Schumpeteriano, terá mais chances de ganhos destacando-se à frente dos demais concorrentes. Esta competição poderá ficar desigual se um dos concorrentes contar com incentivos públicos. Conforme escreve Salomão Filho (1998, p. 190-190) os incentivos para pesquisa tecnológica são instrumentos de política industrial, muitas vezes importantíssimos, até mesmo em face da concorrência internacional e da necessidade de buscar a emancipação tecnológica do país. Mesmo assim defende que as empresas que se incluem nesta política econômica não escapam 
da submissão às normas que regulam a concorrência, inclusive quando for pessoa jurídica de direito público.

Observa ainda o doutrinador que o investimento em desenvolvimento tecnológico é tão prestigiado que pode ser justificativa para aprovar atos de concentração. Tem razão o professor da USP, pois nos termos da lei 12.529/11, em seu Art. 88, § 5', dispõe que "serão proibidos os atos de concentração que impliquem eliminação da concorrência em parte substancial de mercado relevante, que possam criar ou reforçar uma posição dominante ou que possam resultar na dominação de mercado relevante de bens ou serviços". Mas poderá haver exceção, nos termos do $\S 6$, I, "c", na hipótese em que "sejam observados os limites estritamente necessários para atingir os seguintes objetivos: propiciar a eficiência e o desenvolvimento tecnológico ou econômico" (BRASIL, 2011, grifo nosso).

\section{CONSIDERAÇÕES FINAIS}

A Constituição Federal de 1988 definiu de modo expresso políticas públicas que devem ser consideradas prioridades de governos. Entre elas, nesta pesquisa destacou-se a atuação de promover e incentivar o desenvolvimento científico, a pesquisa e a capacitação tecnológicas nos termos estabelecido no Art. 218. Esta opção tem por fundamento a constatação da importância da tecnologia acompanhada da inovação na atualidade, para o cidadão, mercado interno e também ao Estado, garantindo-lhe mais autonomia diante deste conhecimento. Estas são também as finalidades enumeradas no artigo supra referido e no artigo 219 da CF.

O fundamento econômico estudado foram os de Joseph Schumpeter e John Maynard Keynes. O primeiro em face de sua teoria do desenvolvimento e o poder de transformação de que é capaz o regime capitalista aliado à tecnologia inovadora, ao empreendedorismo e o consumo. O segundo porque apoia a intervenção estatal sobre as relações econômicas enfrentando o tradicional pensamento liberal de que ciclos econômicos não são autorregulados. Defende políticas públicas intervencionistas para situações de crise e em setores estratégicos que podem estimular o crescimento econômico.

A partir destes fundamentos defende-se que o Direito poderá ser instrumento para implementação da política pública de desenvolvimento tecnológico, uma vez que a Constituição de 1988 atribui competência aos governos, nos termos do Art. 174, para intervir por meio normativo, fiscalização, 
incentivo e planejamento. Definiu-se pela intervenção por meio do incentivo e seus diferentes meios: tributários, financeiros, subsídios. Este caminho, Norberto Bobbio denomina de técnica de encorajamento e que atualmente é muito utilizado, em concomitância com a tradicional atuação repressiva do Direito. É também uma forma de conduzir condutas, mas por um sistema premial.

Nos termos da Constituição Federal todo investimento público tem controle, até mesmo os incentivos. Para tanto deve haver um conjunto normativo que garanta a constitucionalidade desta opção. Deve inicialmente ter a forma de metas na lei do plano plurianual, seguir para a definição dos instrumentos na lei de diretrizes orçamentária e previsão efetiva de recursos na lei do orçamento. Até esta etapa tem-se a atuação do Legislativo por meio da soberania popular. Segue a execução por meio do Executivo, que fará chegar os recursos por meio de Programas ou outras formas de fomento.

O controle jurídico desta atuação dos governos tem por fundamento e Estado Democrático de Direito. Além do regular trâmite da elaboração e da execução da política pública econômica, supra apresentada, é necessário avaliar a observância do princípio da igualdade e do princípio da livre concorrência. Quanto a igualdade defende-se que nos Art. 218 e 219 estão definidos critérios para aplicação do dinheiro, uma vez que o orçamento público está submetido ao princípio financeiro da reserva do possível.

As prioridades são: I) recursos para órgãos públicos (em sentido amplo) que possam contribuir para as metas do plano plurianual. Nesta categoria os investimentos devem ter preferência: i) para pesquisa científica básica; ii) para pesquisa que contribua, preponderantemente, para a solução dos problemas brasileiros e para o desenvolvimento do sistema produtivo: a) preferência para pesquisas de alcance nacional; b) seguindo para aquelas de alcance regional; iii) para investimentos na formação de recursos humanos nas áreas de ciência, pesquisa e tecnologia, garantindo condições especiais de trabalho; II) recurso para fomentos dirigidos à iniciativa privada e a preferência deve ser: i)para aquelas empresas que invistam em pesquisa, criação de tecnologia adequada ao País; ii) que apresentem programa de formação e aperfeiçoamento de seus recursos humanos na área de tecnologias e inovações; iii) para aquelas que pratiquem sistemas de remuneração e assegurem ao empregado, desvinculada do salário, participação nos ganhos econômicos resultantes da produtividade de seu trabalho.

Quanto a questão concorrencial, as empresas privadas ou públicas que recebem fomentos públicos devem submeter-se ao disposto na Lei 12.529/11. 
Esta dispõe sobre o Sistema Brasileiro da Concorrência e todos que atuam no mercado podem responder repressivamente por condutas anticoncorrenciais, estruturas de mercado que possam afetar a concorrência. Além de submeterse, preventivamente, às regras sobre atos de concentração. Assim, a política pública econômica que concorra de modo efetivo para tais situações poderá ser considerada inconstitucional.

\section{REFERÊNCIAS}

BOBBIO, Norberto. Da estrutura à função: novos estudos de teoria do direito / Norberto Bobbio; tradução de Daniela Beccaccia Versiani; revisão técnica de Orlando Seixas Bechara, Renata Nagamine. - Barueri, SP: Manole, 2007.

BRASIL. Banco Central do Brasil. Agências de fomento. Disponível em: <http://www.bcb.gov.br/pre/composicao/af.asp>. Acesso em 07/10/2014a.

. Constituição Federal de 05 de outubro de 1988. Disponível em: < http://www.planalto.gov.br/ccivil_03/constituicao/ constituicaocompilado.htm>. Acesso em: 07out. 2014.

. Lei $\mathrm{n}^{\circ} \mathbf{1 0 . 9 7 3}$ de 2 de dezembro de 2004a. Dispõe sobre incentivos à inovação e à pesquisa científica e tecnológica no ambiente produtivo e dá outras providências. Diário Oficial da União, Brasília, DF, 3 de dezembro 2004. Disponível em: <http://www.planalto.gov.br/ccivil_03/ _ato2004-2006/2004/lei/110.973.htm>. Acesso em: 07out. 2014.

. Lei $\mathbf{n}^{\circ} 11.080$ de 30 de dezembro 2004b. Autoriza o Poder

Executivo a instituir o Serviço Social Autônomo denominado Agência Brasileira de Desenvolvimento Industrial - ABDI, e dá outras providências. Diário oficial da União, Brasília, DF, 31 de dezembro de 2004. Disponível em: <http://www.planalto.gov.br/ccivil_03/_Ato2004-2006/2004/Lei/L11080.htm> Acesso em 07 out. 2014.

\section{Lei $\mathrm{n}^{\circ} 12.529$ de 30 de novembro de 2011. Estrutura o}

Sistema Brasileiro de Defesa da Concorrência; dispõe sobre a prevenção e repressaõ às infrações contra a ordem econômica; [...] e dá outras 
providências. Diário Oficial da União, Brasília, DF, 1 de dezembro de 2011. Disponível em: <http://www.planalto.gov.br/ccivil_03/_ato2011-2014/2011/ Lei/L12529.htm>. Acesso em: 07 out. 2014.

. Manual de Oslo. Organização para Cooperação e Desenvolvimento Econômico (OCDE)..Disponível em: <http:// download.finep.gov.br/imprensa/oslo2.pdf>. Acesso em: 07out. 2014b.

\section{Ministério do Desenvolvimento, Indústria e Comércio}

Exterior. Apresentação. Disponível em: < http://www.mdic.gov.br/sitio/ interna/interna.php?area=3\&menu=577>. Acesso em: 07 out. 2014c.

BRESSER-PEREIRA, Luiz Carlos. Construindo o Estado Republicano Democracia e reforma da gestão pública. FGV Editora, $1^{\text {a }}$ edição, São Paulo, 2009.

BUTLER, Eamonn. A contribuição de Hayek às idéias políticas e econômicas de nosso tempo. Rio de Janeiro: Instituto Liberal, Editorial Nórdica, 1987.

FURTADO, Celso. O mito do desenvolvimento econômico. Editora Paz

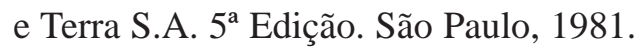

GALVES, Carlos. Manual de economia política atual. $15^{\mathrm{a}} \mathrm{ed}$. Rio de Janeiro: Forense Universitária, 2004.

GENNARI, Adilson Marques e OLIVEIRA, Roberson de. História do pensamento econômico. São Paulo: Saraiva, 2009.

GRAU, Eros Roberto. A ordem econômica na Constituição de 1988. Malheiros Editores. 13a edição. Malheiros Editores. São Paulo. 2008.

JHERING, Rudolf Von. El fin en el Derecho. Editorial Atalaya. Buenos Aires, 1946.

JUGEND, Daniel. DA SILVA, Sérgio Luis. Inovação e Desenvolvimento de Produtos: práticas de gestão e casos brasileiros. Rio de Janeiro: LTC, 2013. 
KELSEN, Hans. Teoria Pura do Direito. Tradução João Baptista Machado. Martins Fontes, São Paulo. 2000.

KEYNES, John Maynard, 1883-1946. Economia/organizador [da coletânea] Tamás Szmrexcsányi; tradução de Miriam Moreira Leite] - São Paulo Ática, 1978; (Grandes Cientístas Sociais).

MENDES, Judas Tadeu Grassi. Economia empresarial. Curitiba, 2002.

PIRES, Adilson Rodrigues. Direito Tributário Volumes I e II. Coord. Schoueri, Luís Eduardo. São Paulo: Quartier Latin, 2003.

SCHAPIRO, Mário Gomes. Política industrial. Fragmentos para um dicionário de direito e desenvolvimento/organizador José Rodrigo Rodriguez. - São Paulo: Saraiva, 2011.

SCHUMPETER, Joseph Alois, 1883-1950. Teoria do desenvolvimento econômico: uma investigação sobre lucros, capital, crédito, juro e o ciclo econômico/Joseph A. Schumpeter; introdução de Rubens Vaz da Costa; tradução de Maria Sílvia Possas. - São Paulo: Abril Cultural, 1982.

. Capitalismo, socialismo e democracia. Introdução de Tom Bottomore. Tradução Sérgio Góes de Paula - Rio de Janeiro: Zahar Editores, 1984.

SALOMÃO FILHO, Calixto. Direito concorrencial: as estruturas. $2^{\mathrm{a}}$ ed. São Paulo: Malheiros, 2008.

Submetido em: 07/10/2014 Aprovado em: 23/11/2014

Como citar: KEMPFER, Marlene; OLIVEIRA, Eduardo Ayres Diniz de. Desenvolvimento tecnológico e a indução jurídica em face da Constituição do Brasil de 1988. Scientia Iuris, Londrina, v.18,n.2, p.145170, dez.2014. DOI: 10.5433/2178-8189.2014v18n2p145. 